\title{
A REALIDADE DAS DECISÕES SOBRE LIBERDADE DE EXPRESSÃO, HONRA E IMAGEM NO STF E NO STJ
}

\author{
THE REALITY OF FREEDOM OF SPEECH, HONOR AND IMAGE RULINGS IN THE BRAZILIAN \\ SUPREME COURT AND SUPERIOR COURT OF JUSTICE
}

Ivar Hartmann

\begin{abstract}
Resumo: $O$ problema da previsibilidade com relação ao que é lícito expressar segundo um sistema jurídico vigente está diretamente vinculado ao chilling effect. O custo para a sociedade da existência de menos opinião sendo expressada em razão da incerteza sobre se o autor será punido mais tarde ou não. Ou seja, não se trata apenas da função de produção de precedentes para dar previsibilidade sobre como o STF e o STJ protegem a liberdade de expressão, honra e imagem, mas também de gerar material autoritativo que aumente as chances do uso de precedentes operacionalizáveis nas instâncias inferiores. $O$ estudo busca responder a pergunta: quais as condições de qualidade da atuação do STF e STJ? O problema de pesquisa é subdividido em quatro: i) com que frequência os tribunais decidem sobre o assunto?; ii) qual o timing das decisões?; iii) as decisões são tomadas em situações que permitam a análise atenta e completa dos fatos e questões jurídicas do caso?; e iv) as decisões são tomadas pelo STF e STJ como órgão colegiado pleno ou fracionário, conforme a previsão constitucional? Os resultados indicam que os tribunais superiores lidam com carga de trabalho que inviabiliza qualquer chance de uma análise do direito infraconstitucional ou constitucional aplicado ao caso concreto. As condições nas quais trabalham os ministros impedem a qualidade da prestação. Os tribunais não decidem como colegiado e transformaram-se em um conjunto de decisões monocráticas.

Palavras-chave: Direitos Fundamentais. Liberdade de expressão. Honra. Imagem. Ponderação. Tribunais superiores. Pesquisa Empírica no Direito.
\end{abstract}

Abstract: The problem of foreseeability on what speech is allowed in a specific legal system is directly related to chilling effect. That is, the cost for society of fewer opinion being expressed due to uncertainty on whether the author will later be punished. It is not merely about the role of producing precedent that will make the STF and STJ jurisprudence on the rights to speech, honor and image more predictable, but also that of generating authoritative material which increases the chances that lower courts will adopt workable precedents. The study seeks to answer the question: what are the conditions for quality of the STF and STJ performance in this role? The research problem is subdivided into four parts: i) how often do these courts rule on the matter?; ii) what is the timing of these rulings?; iii) the rulings are produced under conditions that allow judges careful and complete analysis of the facts and legal issues in the case?; iv) are the rulings issues by the STF and STJ as collegiate (full bench or chamber) bodies, according to constitutional requirement? The results indicate that the high courts deal with a workload that renders impossible any chance of analysis of the legal and constitutional law applied to the case under review. The conditions under which the judges work prevent the quality of the rulings. The courts do not decide as collegiate bodies and have instead transformed in a group of individual rulings.

Keywords: Fundamental rights. Freedom of expression. Honor. Image. Balancing. High Courts. Empirical Legal Research.

Data de submissão: 28 de outubro de 2018 Avaliado em: 01 de novembro de 2018(AVALIADOR A) Avaliado em: 11 de dezembro de 2018 (AVALIADOR B)

Aceito em: 16 de fevereiro de 2019

\footnotetext{
Doutor em Direito Público pela Universidade Estadual do Rio de Janeiro; Mestre em Direito pela Harvard Law School; Professor e Pesquisador na Escola de Direito da Fundação Getúlio Vargas; Praia de Botafogo, 190, Botafogo, 22250-900, Rio de Janeiro, Rio de Janeiro, Brasil; varhartmann@gmail.com; https://orcid.org/0000-0002-8497-6291
} 


\section{Introdução}

Uma das esperanças iniciais em relação à popularização da internet é de que a liberdade de expressão seria potencializada e diversos problemas relacionados à escassez de espaço e censura acabariam perdendo a importância ou força. Qualquer que seja a interpretação sobre a situação atual do exercício da livre manifestação do pensamento, surgiram com a internet e as redes sociais também problemas novos que atualmente preocupam diversas democracias constitucionais. $O$ aparente recrudescimento do discurso de ódio (WALDRON, 2012), a pornografia de vingança (NERI; RUIZ; VALENTE, 2018; HARTMANN, 2018) e as fake news (KLEIN; WUELLER, 2017) exigem, mais do que nunca, que o Direito aprimore os mecanismos de proteção de direitos fundamentais informacionais, aí incluídos a liberdade de expressão e a proteção da honra e da imagem. Em tempos de desconfiança em relação às fontes tradicionais de informação, renova-se a constatação da importância de investigar a qualidade dos mecanismos jurídicos que protegem a opinião e a qualidade das informações (CLÈVE; LORENZETTO, 2016, p. 96).

Portanto, diante dos inevitáveis e renovados conflitos entre liberdade de expressão, honra e imagem que ocorrem na sociedade, qual o papel a ser desempenhado pelos tribunais superiores? A maneira mais simples de ver o problema é que os direitos constitucionais são necessariamente cláusulas abertas e a existência de uma corte constitucional permite ao constituinte resolver um problema por meio de contrato relacional. No caso, os contornos gerais da liberdade de expressão, honra e imagem são definidos, porém especificações e concretizações serão feitas segundo um determinado procedimento no futuro (SWEET, 2012, p. 821).

As partes precisam ter um mínimo de previsibilidade (CAMINKER, 1994, p. 850), de antemão, sobre as chances de sua manifestação vir a ser considerada ilegal mais tarde. Ao produzir precedentes claros e tempestivos sobre liberdade de expressão, as cortes superiores aumentam o custo político dos magistrados que não utilizam esses precedentes.

O Código de Processo Civil de 2015 dá maior destaque que seu antecessor à função do precedente ao estipular exigências específicas sobre o papel dos precedentes e a fundamentação de decisões judiciais. ${ }^{2}$ Ou seja, não se trata apenas da função de produção de precedentes para dar previsibilidade sobre como o STF e o STJ protegem a liberdade de expressão, honra e imagem, mas também de gerar material autoritativo que aumente as chances do uso de precedentes

\footnotetext{
2 São de especial relevância aqui os incisos III e IV do art. 927 ("Art. 927. Os juízes e os tribunais observarão: [...] III - os acórdãos em incidente de assunção de competência ou de resolução de demandas repetitivas e em julgamento de recursos extraordinário e especial repetitivos; IV - os enunciados das súmulas do Supremo Tribunal Federal em matéria constitucional e do Superior Tribunal de Justiça em matéria infraconstitucional;") e os incisos III, V e VI da lista de exigências do art. 489 ("Art. 489. São elementos essenciais da sentença: [...] III - invocar motivos que se prestariam a justificar qualquer outra decisão; [...] V - se limitar a invocar precedente ou enunciado de súmula, sem identificar seus fundamentos determinantes nem demonstrar que o caso sob julgamento se ajusta àqueles fundamentos; VI - deixar de seguir enunciado de súmula, jurisprudência ou precedente invocado pela parte, sem demonstrar a existência de distinção no caso em julgamento ou a superação do entendimento.").
} 
operacionalizáveis nas instâncias inferiores. O problema da previsibilidade com relação ao que é lícito expressar segundo um sistema jurídico vigente está diretamente vinculado ao chilling effect. $\bigcirc$ custo para a sociedade da existência de menos opinião sendo expressada em razão da incerteza sobre se o autor será punido mais tarde ou não. Especificamente sobre o papel dos tribunais superiores, Frederick Schauer defendia que o efeito direto de suas decisões era menos importante para gerar previsibilidade sobre liberdade de expressão do que os efeitos dessa decisão sobre o sistema. ${ }^{3}$ Ao decidirem sobre manifestação do pensamento, portanto, o STF e o STJ precisam dar algum conteúdo normativo minimamente generalizável que extrapole os termos e necessidades do caso específico mesmo que a eficácia da decisão em questão seja inter partes.

Não basta apenas produzir decisões em casos relevantes sobre manifestação do pensamento. Os tribunais superiores precisam garantir que essas decisões possuam um holding claro (MELLO, 2005, p. 180). É dizer, no caso da competência recursal ao enfrentar colisões desses direitos fundamentais, que o STF e STJ devem "demonstrar, argumentativamente, à luz dos elementos do caso concreto, mediante ponderação e uso da proporcionalidade, que determinada solução realiza mais adequadamente a vontade da Constituição, naquela situação específica" (BARROSO, 2015, p. 456) e, mais ainda, apresentar as condições segundo as quais é possível identificar casos parecidos que devam ser decididos da mesma maneira. Seria desejável que mesmo as decisões do STF no controle concentrado tivessem um holding claro que permitisse serem usadas como precedente em decisões futuras que vão além dos dispositivos diretamente afetados, mas não há consenso quanto a essa possibilidade (MELLO, 2016, p. 271).

No que tange à finalidade a ser cumprida pelo STF e STJ no campo da proteção da liberdade de expressão, honra e imagem, portanto, existem exigências de conteúdo das decisões. Mas isso pressupõe que essas decisões sejam tomadas. São considerações de procedimento e operação dos tribunais. Nesse sentido, procurarei testar a produção jurisdicional do STF e STJ sob o ponto de vista do conteúdo e do procedimento.

\section{Justificativa}

Se tentasse empreender estudo empírico para responder à pergunta "as decisões do STF e STJ têm qualidade?", então minha empreitada seria mais complicada. É muito difícil encontrar critérios minimamente aceitáveis para medir a qualidade das decisões (EPSTEIN; MARTIN, 2010, p. 906). O objetivo desse trabalho é contrastar as análises qualitativas com pouco rigor metodológico da atuação de cortes que são a regra na produção acadêmica nacional com análises quantitativas.

\footnotetext{
3 Naquilo que parece uma previsão do volume da carga de trabalho do STF e STJ atualmente, Schauer (1978, p. 731-732) afirma que "[a]s the first amendment comes to embrace new ground [...] the Supreme Court's ability effectively to fulfill its obligation of factual review becomes less and less a realistic possibility. The vitality of first amendment protection thus rests more on the substantive and procedural rules employed below than on the appellate review of the findings made under those rules."
} 
Não há nada de inerentemente melhor em análises quantitativas no campo do direito nacional trata-se apenas de buscar um equilíbrio. As duas metodologias são complementares e a quantitativa ainda é quase inexistente. ${ }^{4}$

Até seria possível realizar análise de conteúdo de maneira quantitativa. Estudos sobre a Suprema Corte norte-americana testaram a hipótese de que briefs de melhor qualidade influenciam mais o conteúdo das decisões da Corte $e^{5}$ ou de que os votos vencedores utilizam linguagem mais agradável para influenciar o apoio popular às decisões. ${ }^{6}$ Para minha pesquisa, entretanto, utilizarei approach majoritariamente quantitativo focado no procedimento dos tribunais superiores.

A qualidade do conteúdo e da performance procedimental das cortes é um resultado possível - e não automático - de um julgador ou grupo de julgadores exercendo sua tarefa constitucionalmente atribuída com um mínimo de condições fáticas para tanto. Aqui me refiro, portanto, a condições de qualidade. São conditio sine qua non para decisões de qualidade (LEAL, 2017, p. 112) que possam viabilizar que os tribunais superiores exerçam sua função no que tange à proteção da liberdade de expressão, honra e imagem.

Parto do pressuposto de que as condições de trabalho dos ministros do STF e STJ influenciam diretamente o mérito e conteúdo das decisões. Essa é uma das premissas de uma já tradicional escola de estudos sobre comportamento de juízes, inaugurada no final da década de 1950 por Herman Pritchett com seu livro "The Roosevelt Court" (Editorial, 1967). A linha de pesquisa acabou por comprovar uma série de motivações ou fatores determinantes para o mérito das decisões judiciais, fazendo com que os membros do realismo jurídico pudessem atacar a noção de jurisprudência mecânica (GOLDMAN, 1971, p. 142) - não é apenas o direito ou as normas jurídicas que guiam as decisões judicias. Um número incontável de estudos em várias décadas jogou luz sobre diversos desses fatores que influenciam o comportamento judicial: a ideologia (orientação política) (SUNSTEIN; SCHKADE; ELLMAN, 2014, p. 352), a atitude em relação a determinados objetos ou relações (ULMER; STOOKEY, 1975, p. 346), o pertencimento a determinados grupos sociais, a experiência do julgador inserido em um grupo de

\footnotetext{
4 "É preciso que fique claro que o pesquisador do Direito é aquele que emprega rigor acadêmico e método para realizar pesquisa teórica ou empírica. Ambas são necessárias e complementares. Ocorre que a pesquisa empírica é muito sub-representada e de execução mais custosa. Isso faz dela hoje um campo mais promissor, com muito mais espaço para ocupar e coisas novas a fazer." (HARTMANN, 2017).

5 A qualidade das petições foi medida de maneira inovadora utilizando técnicas computacionais: "Since scholars cite multiple aspects of writing as consequential for a brief's quality, I measured the quality of briefs along multiple dimensions. The indicators of quality discussed by scholars break down into two categories: those dealing with word choices and those dealing with sentence structure. Judges and Justices appear to be drawn to language and structure that make writing easily comprehensible. To move beyond past measures, I used dictionary-based software. The first tool, StyleWriter 4, provides the indicators for the bulk of the factors associated with brief quality including wordiness, lively language, passivity, and sentence complexity. StyleWriter is writing editor software with settings that can be modified for specific industries and purposes such as law. Style Writer has a built-in 200,000 graded word list and 50,000 word and phrase style and usage checker to analyze the use of plain language." (FELDMAN, 2016, p. 58). Feldman demonstra que a qualidade das petições influencia o tanto o resultado da decisão, quanto a parcela do texto da decisão que é similar ao texto da petição - mesmo controlando pela experiência dos autores das petições no litígio perante a Suprema Corte.

6 A medida de quão desagradável era a linguagem dos votos foi também feita com técnicas computacionais: "For our dependent variable, we use a composite measure generated from three different indicators of disagreeable language taken from two computer-based dictionary programs. Using three measures enables us to be confident in our claims that our measure of disagreeable rhetoric is not contingent on the idiosyncrasies of one computer program." (WEDEKING; ZILIS, 2017, p. 6).
} 
colegas (EPSTEIN; LANDES; POSNER, 2013), a opinião pública (YATES; MOELLER; LEVEY, 2013) e, claro, as características pessoais do juiz (KOPPEN; KATE, 1984), incluindo aí interesses pessoais (SCHAUER, 2000, p. 636) - entre outros fatores.

Optei então por buscar responder à pergunta: quais as condições de qualidade da atuação do STF e STJ? Meu problema de pesquisa é subdividido em três: i) com que frequência os tribunais decidem sobre o assunto?; ii) qual o timing das decisões?; iii) as decisões são tomadas em situações que permitam a análise atenta e completa dos fatos e questões jurídicas do caso? ; e iv) as decisões são tomadas pelo STF e STJ como órgão colegiado pleno ou fracionário, conforme a previsão constitucional?

\section{Metodologia}

Produzi dados quantitativos que respondem essas três subperguntas e, assim, contribuem para uma resposta ao problema de pesquisa que seja fundamentada em evidências e não em mera retórica ou escolhas arbitrárias. Para levantar dados sobre as condições de qualidade das decisões do STF e STJ, adotei método de pesquisa empírica, com técnica quantitativa. Os dados foram levantados usando as bases de dados do projeto XXXX da XXXX.

As bases do STF e STJ contêm os processos autuados entre 1988 e final de 2017 em formato MySOL, incluindo, no caso do STF, dados sobre 1.882.344 processos, 2.098.769 partes e 23.167.583 registros de andamentos. No caso do STJ, são 5.194.722 processos, 7.327.756 partes e 100.089.221 registros de andamentos. Também fazem parte da base meta-dados sobre os processos como o assunto jurídico, o órgão judicial de origem e o estado de procedência, entre outras. Os andamentos abrangem informações sobre datas e resultados de decisões tomadas durante os processos, datas de distribuição dos processos, datas de conclusão ao relator do processo, trânsito em julgado e similares. Os principais dados ou variáveis sobre os quais se ancoram os levantamentos dessa pesquisa encontram-se associados aos andamentos processuais e são a origem da decisão - qual ministro responsável, se monocrática, ou qual órgão colegiado; tipo da decisão - liminar, de mérito ou interlocutória; e resultado - concessão, não concessão, não admissão, etc.

A pesquisa abrange levantamentos que retratam o processo decisório dos dois tribunais superiores como um todo, para obter uma base de comparação, bem como levantamentos específicos sobre o universo de processos sobre conflitos entre liberdade de expressão, honra e imagem. Para tanto, são identificados os processos aos quais os servidores do tribunal atribuíram tal assunto como crime de calúnia - e todos aqueles que, mesmo não tendo sido catalogados em assuntos desse tipo pelo tribunal, possuem em suas decisões a ocorrência de termos ligados à matéria. A expressão de busca utilizada é "("manifestação pensamento" 4 OR "liberdade expressão" 4) AND (honra OR imagem OR reputação) AND ("dano moral" OR "danos morais")". 
Dessa forma, e é conveniente reiterar essa escolha metodológica, o objetivo dessa pesquisa não é comparar as condições de decisão da liberdade de expressão, proteção da imagem e honra em três grupos separados. Pelo contrário: o foco é justamente a atividade comum no Judiciário nacional de resolver os conflitos entre esses direitos fundamentais.

\section{Resultados}

i) Com que frequência os tribunais decidem sobre liberdade de expressão, honra e imagem?

O primeiro dado relevante é sobre o universo de processos desse tipo em casa tribunal. $\bigcirc$ Gráfico 1 mostra a concentração desses processos no STF e no STJ.

Gráfico 1 - Processos sobre Liberdade de Expressão, Honra e Imagem nos Tribunais Superiores, em \% do Total (1989-2017)

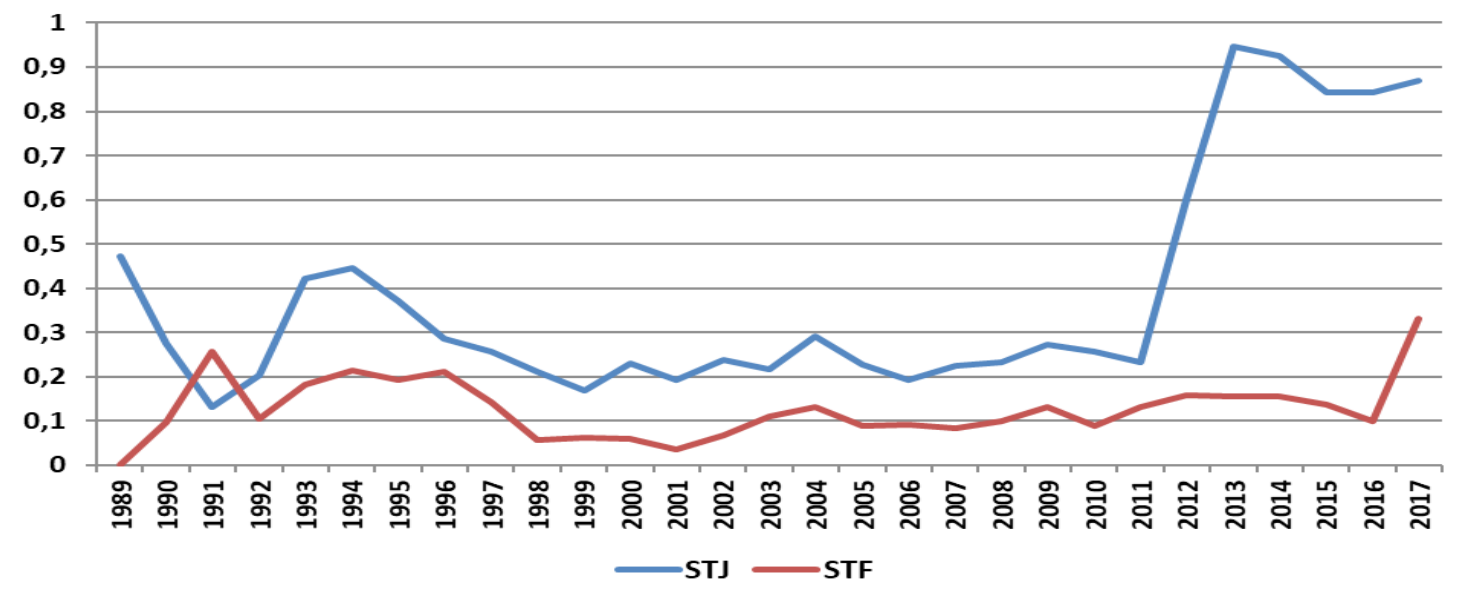

Fonte: os autores.

A concentração de processos dessa área é historicamente ínfima em ambos os tribunais. Mesmo após grande aumento no STJ a partir de 2011, ela nunca chegou sequer a 1\%. No STF, apenas em 2017 ela ultrapassou a barreira de 0,3\%. Para um tema aparentemente popular no Judiciário e que, além do mais, cuida de diversos direitos da personalidade em conflito, algo central para o direito privado nacional, parece pouco. Por outro lado, se considerarmos os dados da empresa Kurier, já mencionados, em todo o Judiciário brasileiro a concentração de processos ligados a "liberdade de expressão" é de 0,13\%. De qualquer forma, essa situação no STF e STJ não é exclusividade desses direitos da personalidade. Os Gráficos 2 e 3 mostram que conflitos de direitos fundamentais com pouca concretização normativa a nível constitucional ou legal não ficam entre os assuntos mais comuns na pauta. 


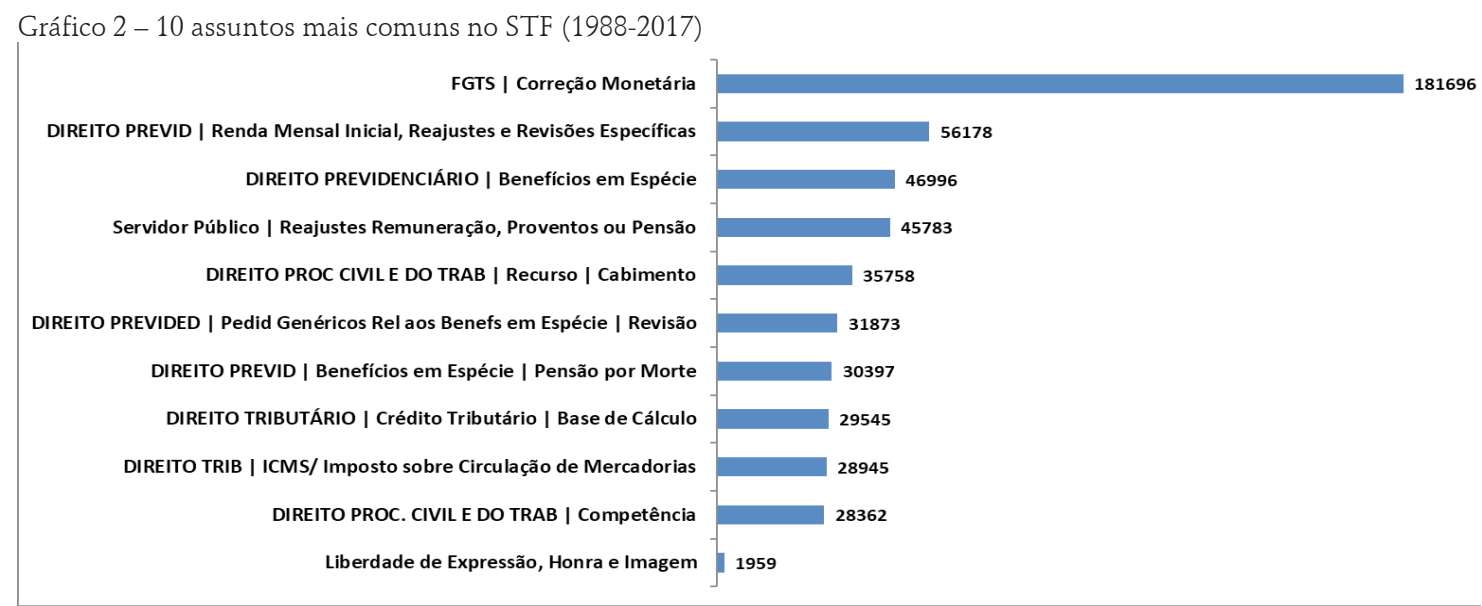

Fonte: os autores.

No STF os assuntos mais comuns estão relacionados a direito tributário e previdenciário, além de questões de servidores públicos. O total de processos do campo discutido aqui é de 1959 entre 1988 e 2017.

Gráfico 3 - 10 assuntos mais comuns no STF (1988-2017)

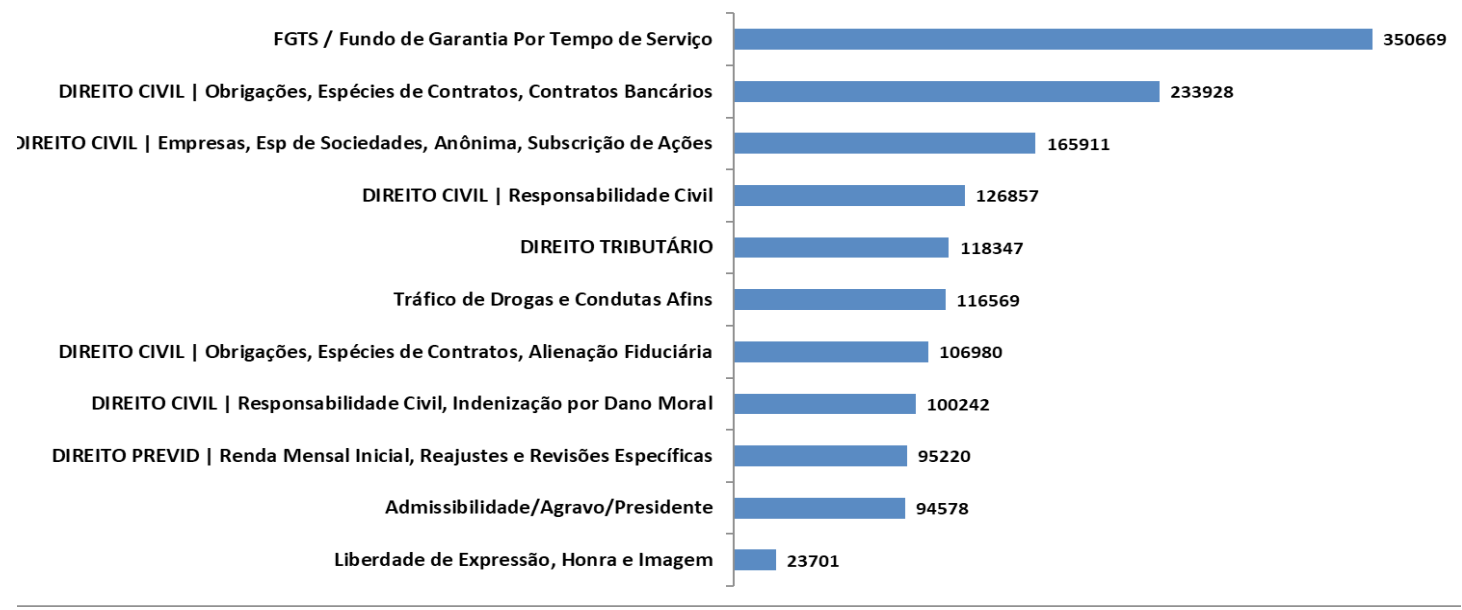

Fonte: os autores.

No STJ o panorama é ligeiramente diferente. Os assuntos mais frequentes incluem mais questões de direito civil - metade dos 5 assuntos com maior volume de processos no período. Mas a diferença entre o $10^{\circ}$ assunto mais frequente e o campo de liberdade de expressão, honra e imagem é muito inferior àquela encontrada no STF. Enquanto no STJ liberdade de expressão representa 25\% do $10^{\circ}$ assunto, no STF representa $6,9 \%$.

ii) Qual é o timing das decisões? 
Em resposta ao velho "a justiça tarda, mas não falha", muitos ponderam que a justiça que tarda, falha. No caso da liberdade de expressão e especialmente para os tribunais superiores, a demora em produzir precedentes que sirvam de guia para a aplicação do direito constitucional ou infraconstitucional em todo o Brasil tem efeito não apenas nos processos específicos sendo julgados pelo STF e STJ, mas em dezenas de milhares no Judiciário nacional. A produção de determinados paradigmas para pacificar novas controvérsias sobre o tema, especialmente em razão dos avanços tecnológicos, depende de alguma agilidade desses dois tribunais.

Foram identificados os andamentos de trânsito em julgado e computada a diferença em dias entre a data desse andamento e a data de autuação do processo. A título de comparação, o mesmo dado é mostrado para a totalidade dos processos do tribunal.

Gráfico 3 - Dias até Trânsito em Julgado de Processos no STF (1990-2017)

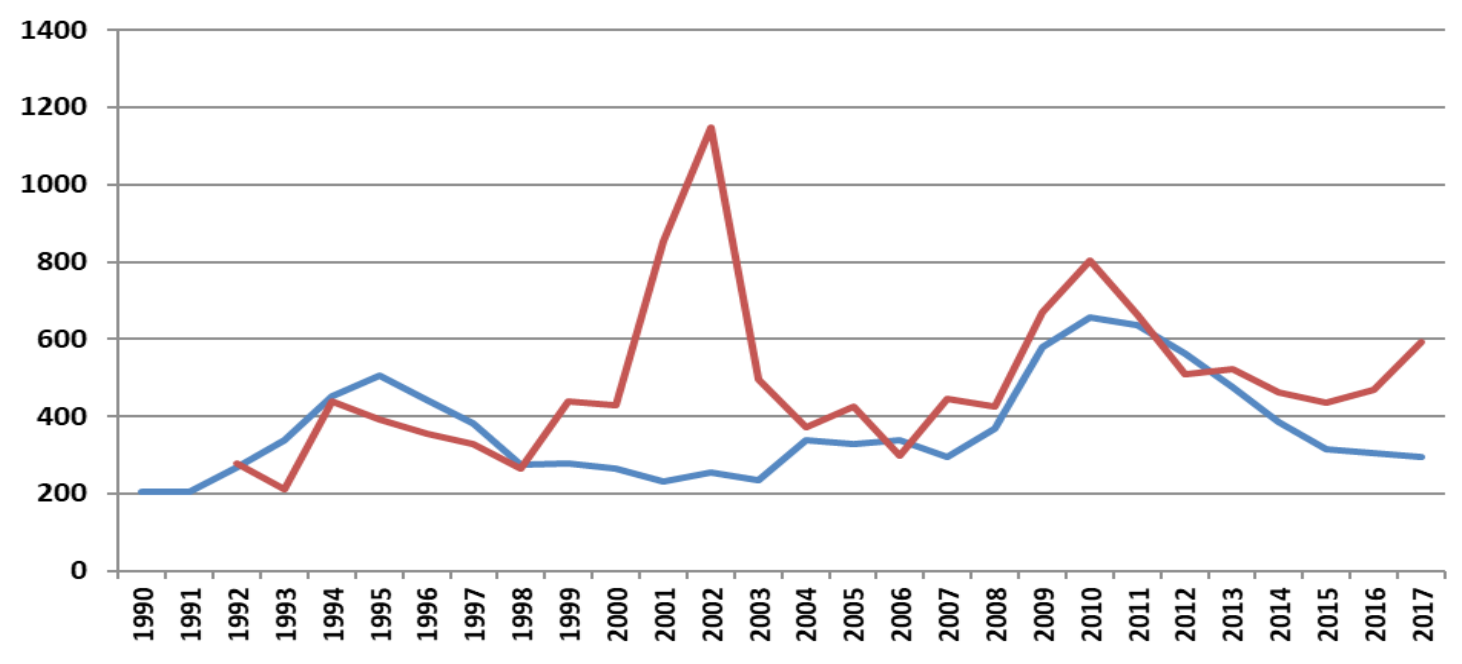

Geral Lib Expressão

Fonte: os autores.

G Gáfico 4 mostra que no STF os processos do tema levaram mais tempo para serem decididos do que os demais. Isso ocorreu em diversos períodos, como entre 1998 e 2006 e inclusive parece estar se acentuando desde 2013. Em 2017, um processo transitando em julgado no STF havia iniciado em média 294 dias antes. Já aqueles de liberdade de expressão, honra e imagem haviam sido autuados 594 dias antes. 
Gráfico 4 - Dias até Trânsito em Julgado de Processos no STJ (2014-2017)

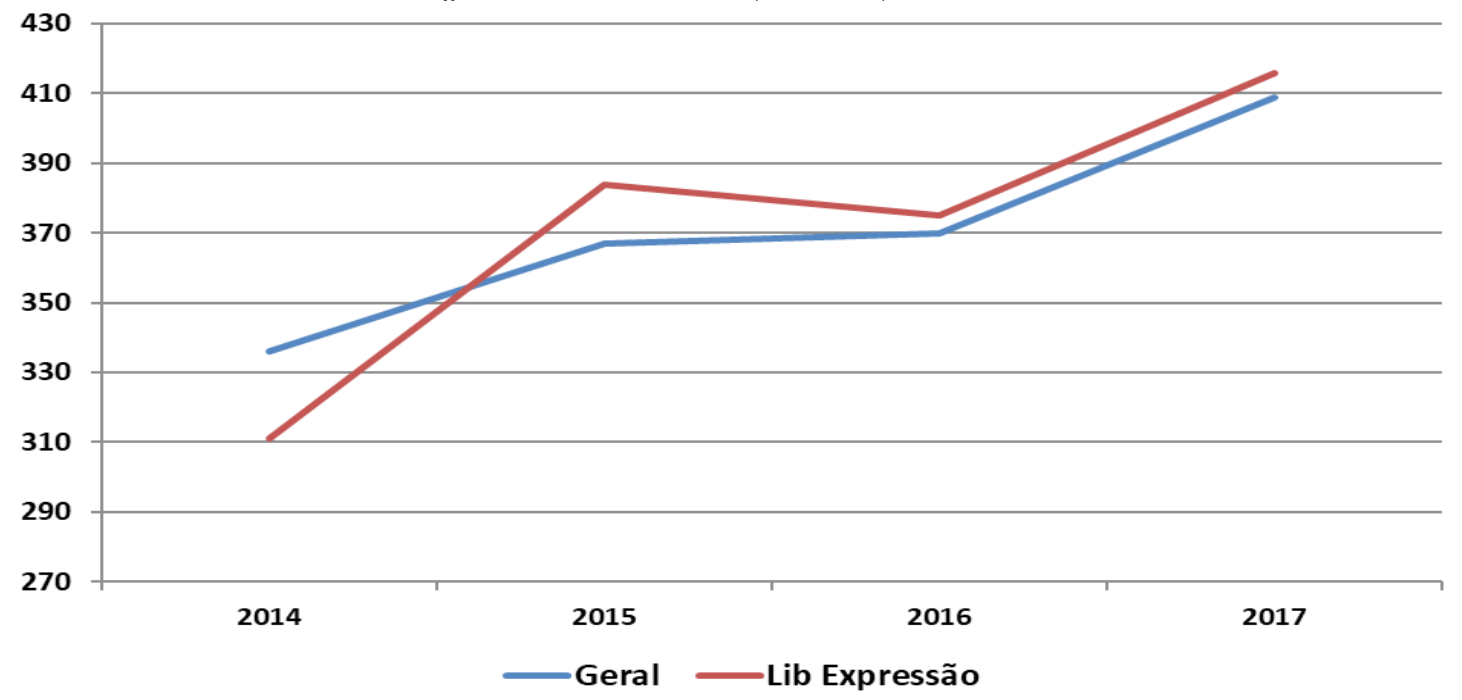

Fonte: os autores.

No STJ a maneira como as informações sobre os andamentos são lançadas não permite a análise em períodos anteriores a 2014. Não obstante, em um intervalo de 4 anos é possível perceber que o tratamento entre os processos em geral e aqueles sobre o tema específico é muito pouco diferente. Mesmo no ano com maior intervalo entre as duas durações, em 2015, ele foi de apenas 17 dias.

Há uma evidente diferença entre o papel exercido pelo STF ao decidir sobre o conflito entre manifestação do pensamento, honra e imagem em concreto e inter partes, como é o caso de mais de $99 \%$ dos processos do recorte, ${ }^{7}$ e em abstrato e erga omnes. No segundo caso, a passagem do tempo sem prestação jurisdicional tem efeito direto e custo maior. É importante avaliar em separado, portanto, o timing das decisões do STF no controle concentrado. Serão considerados o tempo entre o início do processo e a decisão liminar em um gráfico e o tempo entre o início e a decisão de mérito em outro.

\footnotetext{
7 São apenas 13 processos no controle concentrado de constitucionalidade. Há indícios, entretanto, de que esse número pode ser maior. Muitos processos relevantes foram catalogados com assuntos genéricos, como as ADIs sobre direito de resposta. A 5415 foi catalogada como "DIREITO ADMINISTRATIVO E OUTRAS MATÉRIAS DE DIREITO PÚBLICO | Garantias Constitucionais" e "DIREITO ADMINISTRATIVO E OUTRAS MATÉRIAS DE DIREITO PÚBLICO | Controle de Constitucionalidade", a 5418 como "DIREITO ADMINISTRATIVO E OUTRAS MATÉRIAS DE DIREITO PÚBLICO | Garantias Constitucionais |Comunicação Social" e a "DIREITO ADMINISTRATIVO E OUTRAS MATÉRIAS DE DIREITO PÚBLICO | Controle de Constitucionalidade".
} 
Gráfico 5 - Dias até Decisão Liminar pelo Plenário no Controle Concentrado do STF (1989-2017)

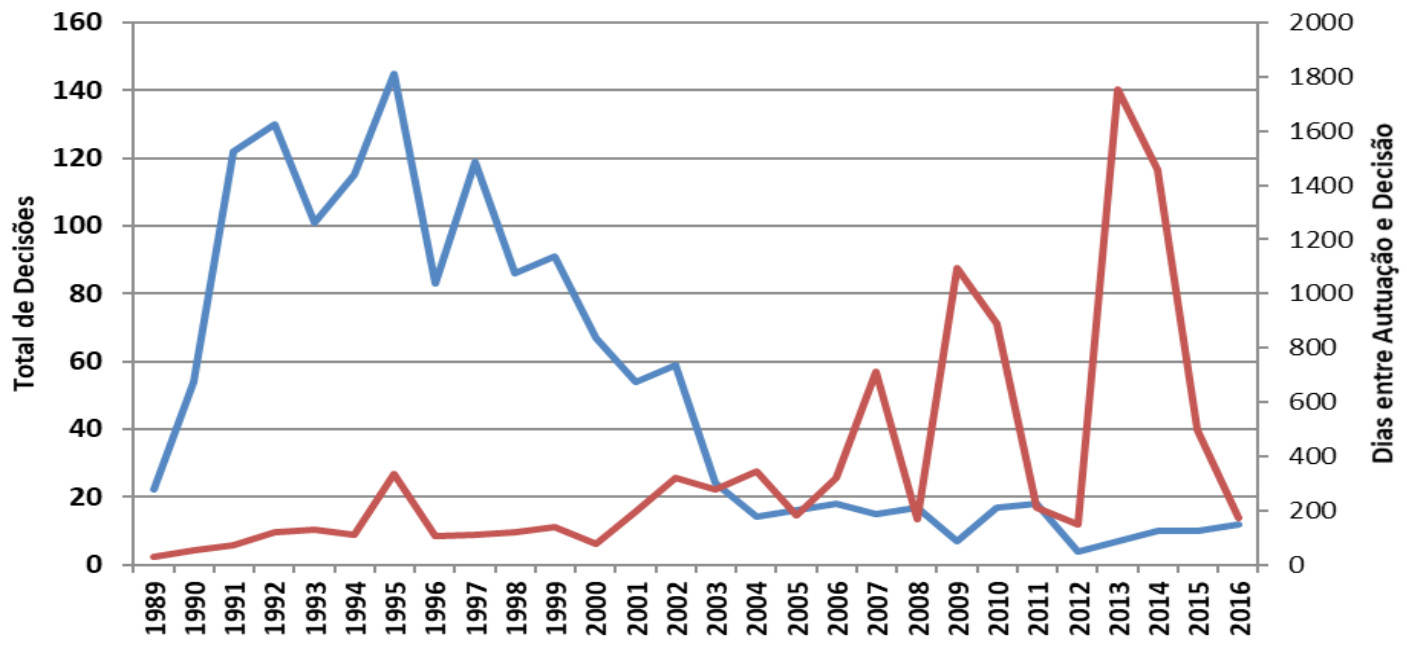

Total de Decisões Dias

Fonte: os autores.

O volume do subgrupo liberdade de expressão é pequeno demais para traçar uma comparação estatística. Existem picos de grande demora para a análise da liminar pelo plenário nos de 2009 e 2013, possivelmente devido à escolha de pedidos liminares que aguardavam a análise há muito tempo. Nesses anos as liminares decididas aguardavam em média há 1096 e 1754 dias, respectivamente. Em 2016 a média foi de 173 dias.

Gráfico 6 - Dias até Decisão de Mérito pelo Plenário no Controle Concentrado do STF (1989-2017)

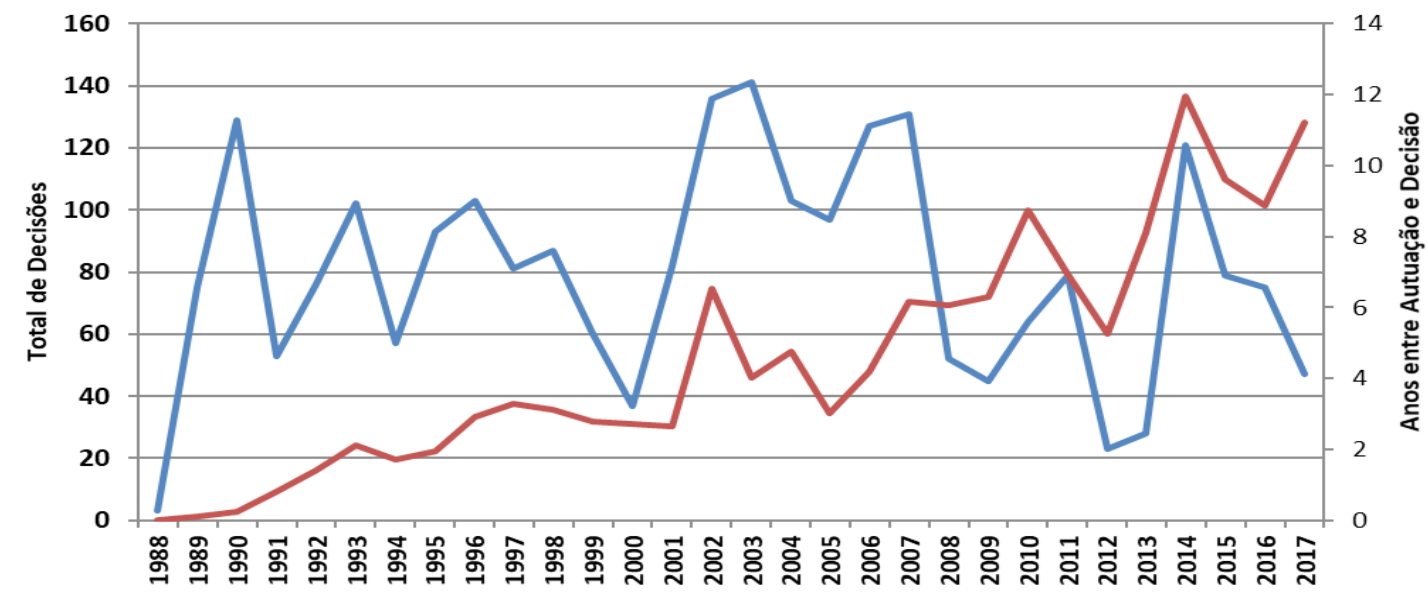

Total de Decisões Dias

Fonte: os autores. 
No caso das decisões de mérito, o padrão é parecido, porém com menos variações em intervalos pequenos de anos. Desde 1994 a média não fica abaixo de 2 anos. Os processos do controle concentrado decididos pelo plenário em 2017 haviam sido iniciados, em média, 11 anos antes.

A comparação com o cenário no campo da liberdade de expressão exige a observação de alguns exemplos. As ADIs sobre a lei do direito de resposta aguardam decisão de mérito há mais de 2 anos. A ADI 4815, sobre biografias não-autorizadas, levou três anos para ser julgada. A ADI 869, sobre a suspensão por dois dias de veículos que houvessem divulgado, sem autorização, informações relacionadas a procedimentos policiais, administrativos ou judiciais envolvendo crianças foi autuada em maio de 1993 e decidida em agosto de 1999.

Ao menos no controle concentrado, portanto, a performance do STF parece ser melhor para os casos de liberdade de expressão. Mas uma leitura realista dos dados exige ao menos duas considerações. Primeiro, o teto de espera apontado pelos casos em geral é assustador. Qualquer nova ação pode ficar dentro dessa média e levar 11 anos para ser analisada pelo plenário. Mesmo levando em consideração que o Judiciário não pode e não deve se manifestar sobre novos problemas no exato ritmo em que eles surgem na sociedade, um gap de mais de uma década seria prejudicial em qualquer área do direito. Quando a liberdade de expressão e o litígio sobre ela, como mostraram os dados do TJ-RJ, cada vez mais envolve a internet ou se dá exclusivamente online, a velocidade da evolução dos temas e novas controvérsias de valor jurídico é mais rápido do que em outros campos. Um ano é uma eternidade em tempo da internet. A questão da responsabilidade de intermediários sobre conteúdo compartilhado por terceiros na internet teve sua repercussão geral reconhecida pelo STF em março de 2012, há quase 6 anos. Nesse período o Facebook foi de 901 milhões de usuários no mundo para 2.072 bilhões (NUMBER..., [201-]).

Segundo, e talvez mais importante, a incapacidade dos tribunais superiores de produzir precedentes claros e operacionalizáveis sobre liberdade de expressão é um dos principais fatores de intensificação do chilling effect, conforme já discutido. Não há como compensar a manifestação voluntariamente suprimida com correção monetária e taxa de juros. Quando plataformas com centenas de milhões de usuários realizam escolhas de arquitetura e de políticas de conteúdo temendo pelo pior, essa censura deixa de ser voluntária para todos aqueles que tem seu conteúdo removido mais rapidamente e com maior frequência. $O$ resultado de insegurança em relação ao standard de responsabilidade civil tem efeito nocivo e capilarizado. Esse é o custo da espera pela decisão do STF desde março de 2012. Para a segurança jurídica e a previsibilidade dessas empresas, não constitui garantia suficientemente segura à adoção, pelo Marco Civil da Internet no Brasil, do standard da notificação judicial em seu art. 19. Desde então, muitos juristas qualificados (SCHREIBER, 2015) e magistrados têm entendido que o dispositivo é inconstitucional por proteger de maneira deficiente a honra e a imagem.

iii) As decisões são tomadas em situações que permitam a análise atenta e completa dos fatos e questões jurídicas do caso? 
Não existem regras específicas sobre quais as condições mínimas necessárias para que os ministros possam se dedicar aos casos de modo a avalia-los de forma atenta e completa. Mas existem certos fatores que afetam as condições e, ao menos indiretamente, afetam a qualidade das decisões. Aqui não farei avaliações do conteúdo das decisões. Uma pesquisa revelou que, sob o ponto de vista do conteúdo, as decisões monocráticas no STF parecem ser repetitivas. Uma em cada três delas possuíam trechos com 130 caracteres ou mais que eram idênticos aos encontrados em outras decisões. Dentre essas decisões com longos trechos idênticos, $20 \%$ do seu inteiro teor era idêntico ao de outras decisões (HARTMANN; CHADA, 2017). É a confirmação da produção fordista da prestação jurisdicional da Corte Constitucional, à qual os ministros estão invariavelmente submetidos em razão da avalanche de demandas repetitivas.

Aqui, entretanto, pretendo abordar três características das decisões que podem afetar sua qualidade: o número de decisões produzidas em um único dia ou único mês, a concentração de decisões colegiadas e, exclusivamente para o STF, a presença dos ministros nos julgamentos colegiados.

A sobrecarga dos tribunais superiores não é nenhuma novidade e foi especialmente caracterizada no I Relatório Supremo em Números (FALCÃO; CERDEIRA; WERNECK, 2011). Meu objetivo aqui é apenas retratar com alguns recortes novos a competição brutal que enfrentam os processos de liberdade de expressão pela atenção dos ministros e seus gabinetes. Nos últimos 10 anos o STF produziu 976.111 decisões liminares, terminativas de mérito ou sobre recursos internos. Isso significa que nesse período cada ministro e seu respectivo gabinete elaborou uma média de 24 decisões por dia - presumindo nenhum dia de descanso. Mas existem feriados, finais de semana, férias, recesso e assim por diante. Se considerarmos apenas 200 dias úteis no ano, são 44 decisões. Em determinados dias, entretanto, quando o número produzido é maior, as condições de trabalho podem estar ainda mais prejudicadas.

Gráfico 7 - 10 Dias com o Maior Número de Decisões Publicadas no STF (2008-2017)

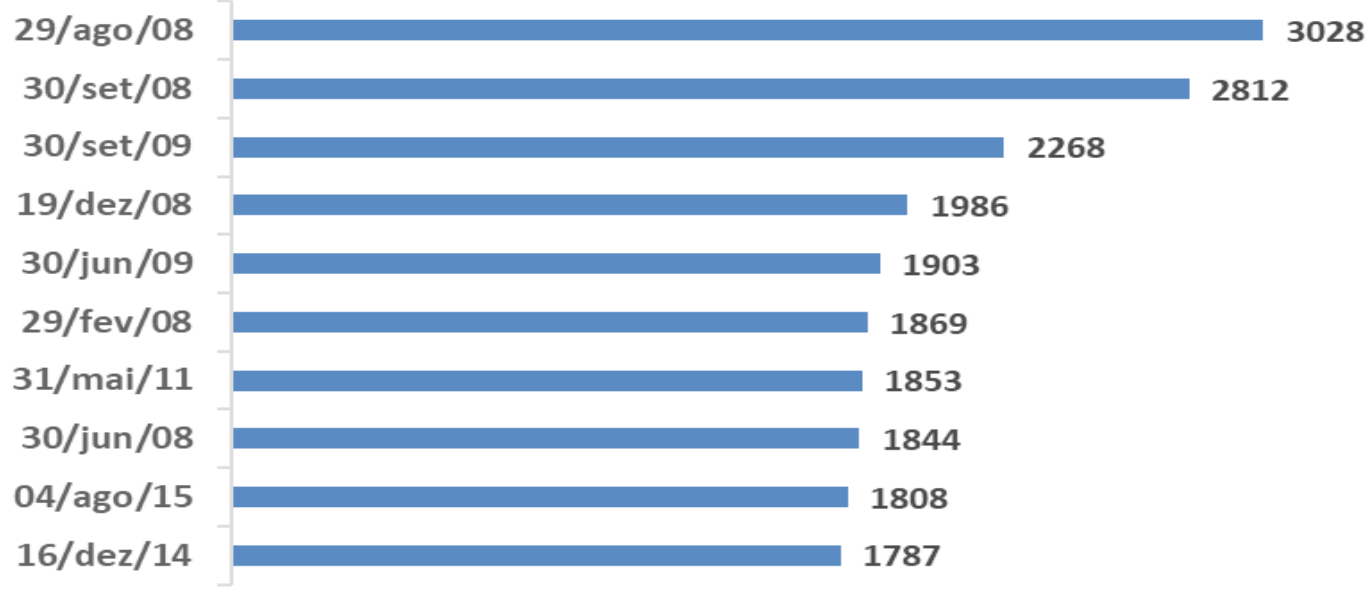

Fonte: os autores. 
Em muitos dias o número de decisões publicadas ultrapassa mil. A realidade é que existe um número massivo de recursos repetitivos que chegam ao STF, bem como uma quantidade enorme de recursos internos insurgindo-se contra questões já totalmente pacificadas. É comum, por exemplo, que uma grande quantidade de embargos de declaração protelatórios seja decidida com menor necessidade de análise. Ainda assim, resta um volume ainda muito grande de decisões.

Gráfico 8 - 10 Dias com o Maior Número de Decisões pela Procedência ou Procedência Parcial do pedido Publicadas no STF (2008-2017)

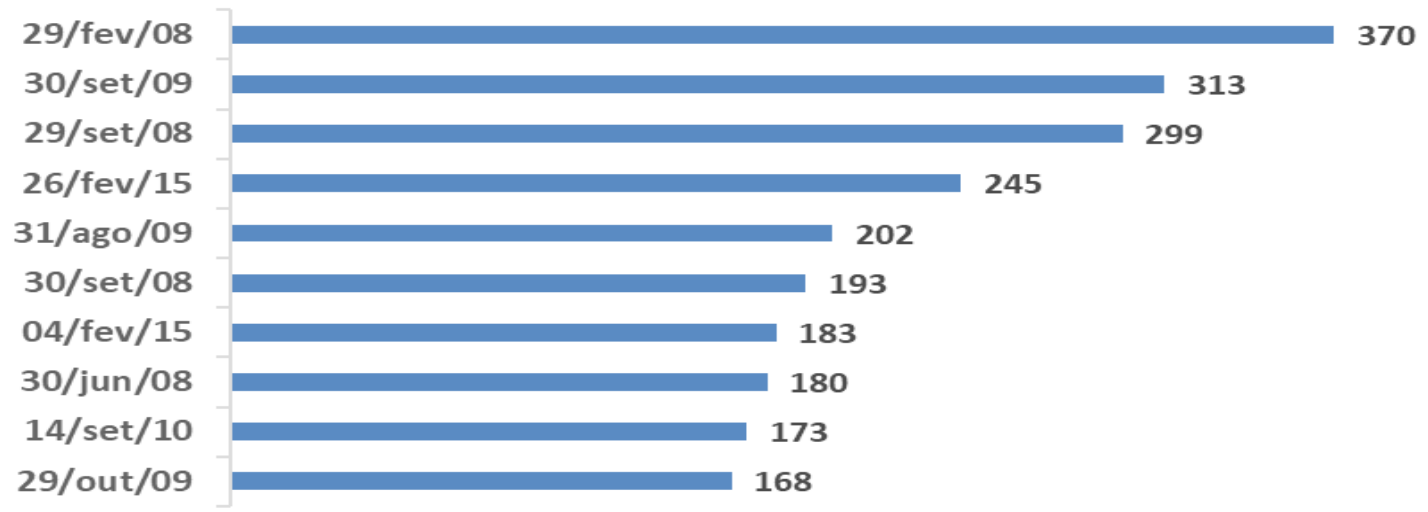

Fonte: os autores.

No $10^{\circ}$ dia com o maior número de decisões concessivas a soma ainda significa uma média de mais de 10 por ministro. A carga de trabalho se manifesta, portanto, de forma decisiva sobre as condições de qualidade para tomada de decisões no STF. No STJ o panorama é similar.

Nos últimos 10 anos o tribunal produziu 4.462 .022 decisões. Isso significa 37 decisões por dia, por ministro. Ou 67 decisões por dia, por ministro, se considerados apenas 200 dias úteis anuais. Mas muitos dias aglomeram volume surreal de decisões.

Gráfico 9 - 10 Dias com o Maior Número de Decisões Publicadas no STJ (2008-2017)

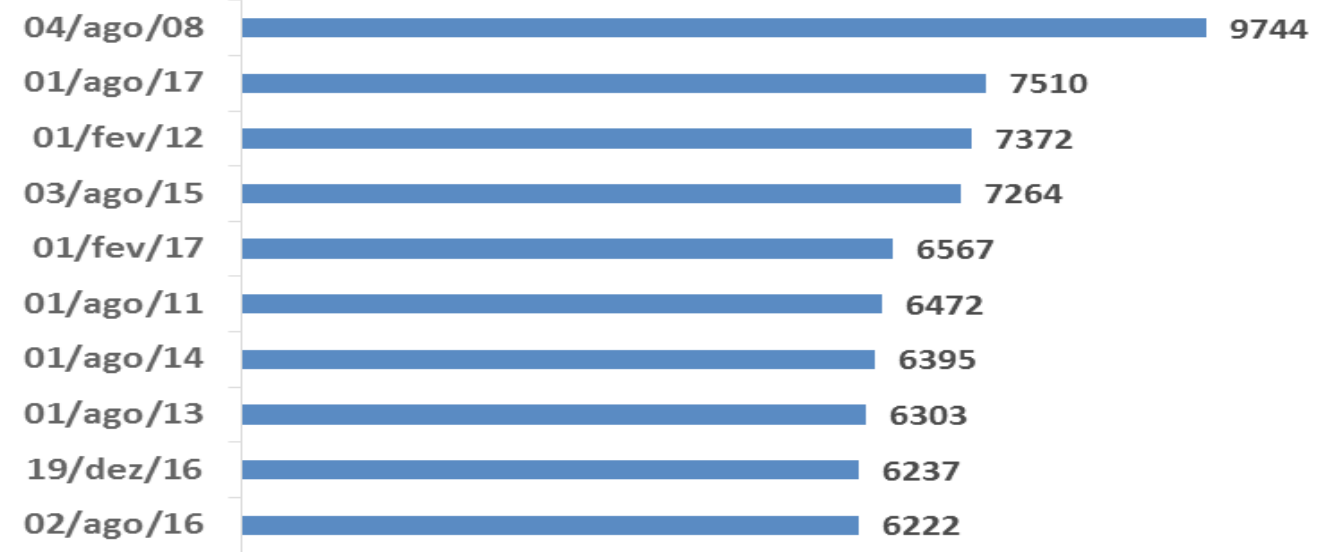

Fonte: os autores. 
No primeiro dia de fevereiro de 2017 o STJ publicou 6567 decisões. São quase 200 decisões por ministro em um único dia. Um desafio mesmo para os gabinetes mais eficientes, mas que deixa dúvida sobre as chances de que um hard case envolvendo liberdade de expressão, honra e imagem tenha recebido a devida atenção.

O segundo aspecto que afeta as condições de qualidade das decisões é a quantidade de ministros envolvidos na sua produção. A Constituição fez uma escolha pela colegialidade no STF e no STJ por razões de representatividade e diversidade 8 de pontos de vista. Além disso, existe a ideia, expressada pelo Teorema de Condorcet, de que as chances de uma decisão ruim sobreviver ao crivo de diversas pessoas em um colegiado são menores do que as chances de sobreviver à avaliação de apenas uma pessoa. Não estou aqui pressupondo de maneira idealista que as decisões colegiadas no STF e STJ correspondam, na prática, às expectativas de deliberação tradicionalmente atribuídas aos tribunais superiores. As decisões no STF são afetadas por diversos fatores que comprometem a qualidade da deliberação (SILVA, 2013), como por exemplo a transmissão pela TV Justiça. ${ }^{9}$ Muitos acreditam que a transmissão pela televisão ou, mesmo na ausência dessa, a hiperexposição de ministros do STJ e STF traz estímulos adicionais, nem sempre com bons resultados, ao incentivo natural que cada indivíduo tem de escolher a opção que considera mais correta. ${ }^{10}$ Ou seja, não endosso aqui uma adoção sem cuidado do Teorema de Condorcet, até porque sua aplicação depende de certas circunstâncias relacionadas à aleatoriedade na composição do órgão colegiado (EDELMAN, 2002).

Os últimos dois elementos que quantifico aqui por acreditar que possuem impacto sobre a qualidade das decisões são a característica colegiada das decisões e a composição real dos órgãos colegiados durante os julgamentos. Mesmo ciente de que na melhor das hipóteses - um julgamento pelo plenário com todos os ministros presentes - a deliberação não será perfeita, acredito esses dois fatores podem ainda assim ter impacto negativo. De um lado, qualquer que seja o efeito da hiperexposição dos ministros, ele os afeta nas decisões monocráticas também. De outro, os problemas da deliberação nos órgãos colegiados tendem a piorar com menor número de presentes. Alternativamente, a monocratização dos tribunais superiores e a baixa taxa de comparecimento às sessões podem ser considerados negativos meramente porque destoam da determinação

\footnotetext{
8 "As an application, consider a chief executive who assembles a team of experts to determine whether to drill for oil on a given parcel of land. Assume that each expert would favor one alternative and assume for simplicity that each expert's advice is correct with probability p.Condition (4) states that to arrive at the correct decision with a probability greater than $p$, the chief executive should choose experts who represent different, perhaps opposing, schools of thought. Indeed, under certain assumptions specified later, with $p>.5$, the lower the value of $p$ for the advisory team, the higher the value of $P_{n}$ implying that the chief executive should seek advisers who represent a greater diversity of opinion." (LADHA, 1992, p. 627).

9 Testar a hipótese de que a deliberação é afetada negativamente pelas transmissões é um passo que pressupõe outro mais simples. Em primeiro lugar, é preciso saber se a deliberação é de alguma forma afetada. Um estudo de diversos pesquisadores, exigindo a cuidadosa análise de mais de 400 decisões por cada um dos participantes, permitiu afirmar que há sim um efeito na transmissão pela TV Justiça das sessões do pleno (HARTMANN et al., 2017).

10 "The Condorcet Jury Theorem and its extensions assert that under certain conditions, the probability that a collective chooses the correct alternative by majority vote exceeds the probability that any constituent member of the collective would unilaterally choose that alternative. Implicit in these conditions is the assumption that individuals behave in the collective decision exactly as they would if choosing alone (and that such voting is informative). The intuition that an assumption of "sincere" voting is innocuous here turns out to be faulty. Although there is certainly no incentive or opportunity for individual gain at the expense of others, it does not follow that rational individuals behave identically in collective and in autarkic decision-making environments." (AUSTEN-SMITH; BANKS, 1996, p. 43).
} 
constitucional. Meu ponto, portanto, é que independentemente da real qualidade das decisões do STJ e STF, existem fatores que podem sempre operar de maneira a compromete-la ainda mais.

Passo aos dados sobre a frequência das decisões colegiadas no STF e STJ. Algumas alterações legais e regimentais abriram espaço para a atuação monocrática em situações excepcionais. Mas a exceção tornou-se a regra, especialmente na última década.

Gráfico 10 - Decisões Colegiadas no STF, em \% do Total (1988-2017)

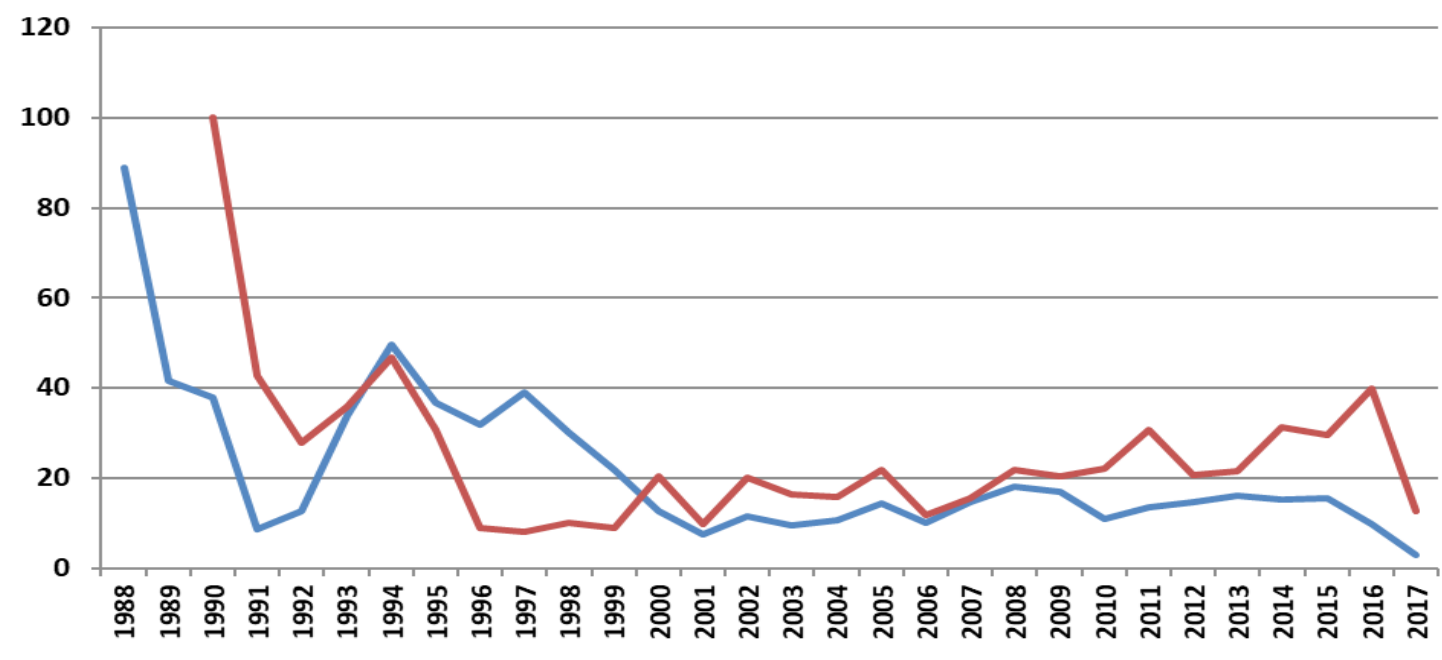

Geral Lib Expressão

Fonte: os autores.

No STF as decisões sobre liberdade de expressão ocorrem de maneira colegiada com maior frequência do que no geral. Essa é a tendência em praticamente todos os anos, com exceção apenas ao período entre 1994 e 2000. Mas a média geral é estarrecedora. Desde 2000, a concentração anual de decisões colegiadas nunca chegou a um quinto do total. A partir de 2016 a tendência é de nova queda, causada pelo uso das decisões colegiadas virtuais. O Gráfico 11 mostra isso.

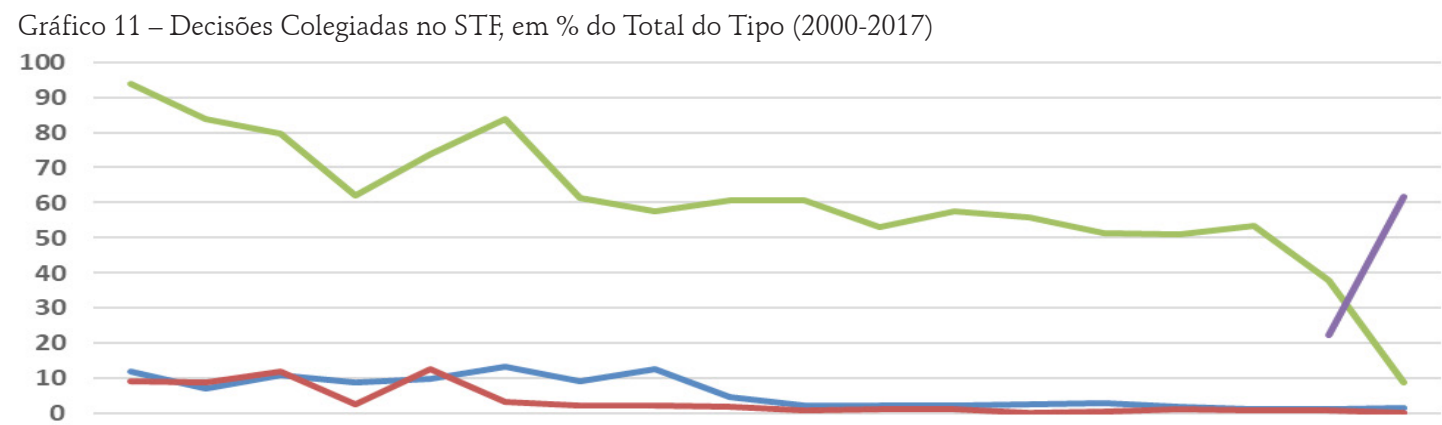

200020012002200320042005200620072008200920102011201220132014201520162017

Mérito Presencial

Liminar Presencial

Recurso Presencial

Recurso Virtual

Fonte: os autores. 
Por não preencherem as condições mínimas de debate que orientam a escolha pelas decisões coletivas, não considerei aqui decisões do plenário virtual ou as sessões virtuais do STF como sendo propriamente decisões colegiadas.

Apenas porque as decisões sobre liberdade de expressão, honra e imagem são tomadas colegiadamente com maior frequência do que no geral, isso não significa que a situação delas seja objetivamente boa em termos de condições de qualidade. Desde 1995 a concentração de colegiadas nesse campo fica abaixo de 40\%, com exceção de 2016. Na maioria dos anos da série histórica ela fica muito mais próxima de $20 \%$ do que de $40 \%$. As decisões colegiadas tornaram-se a exceção, mesmo sobre esse assunto. $\bigcirc$ prognóstico para os anos seguintes é pessimista, já que as decisões coletivas virtuais causaram a queda da frequência de colegiadas presenciais em 2017 para o menor valor desde 2006: $12,5 \%$.

Gráfico 12 - Decisões Colegiadas no STJ, em \% do Total (2001-2015)

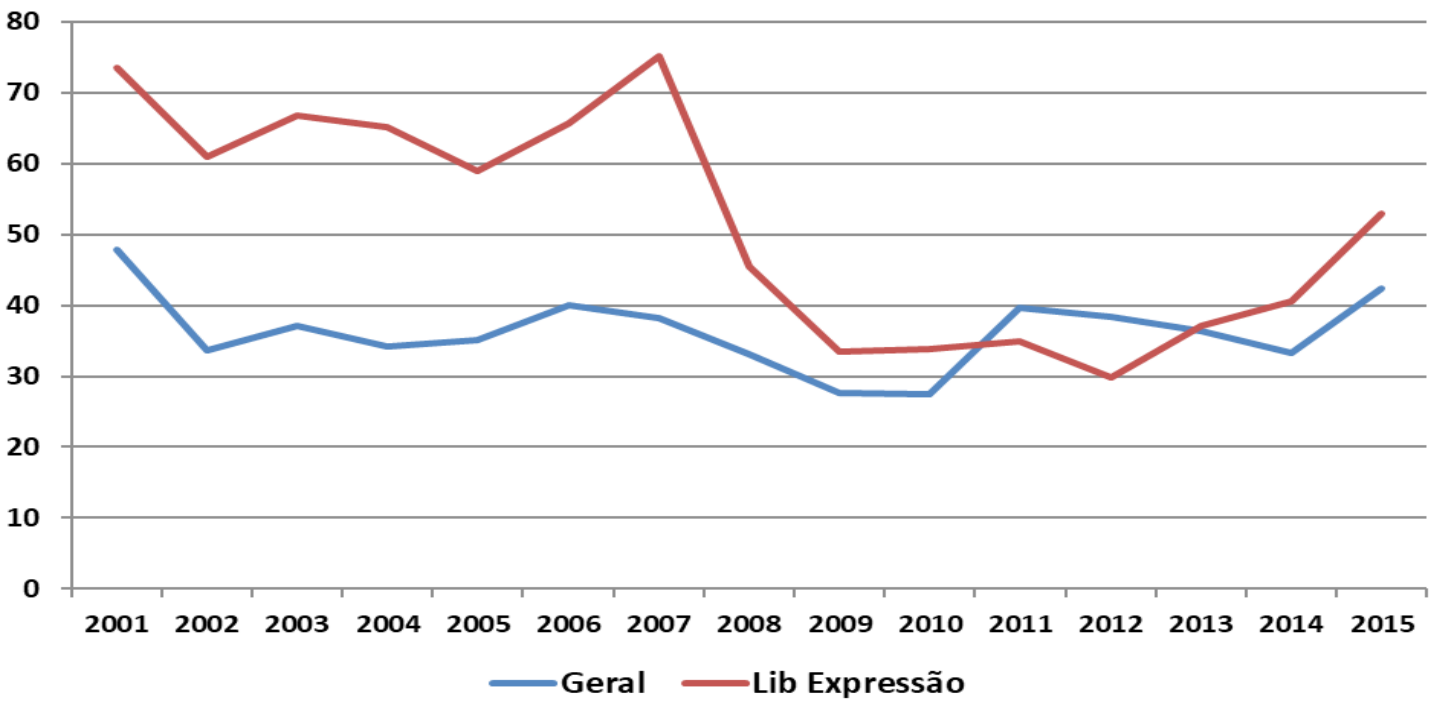

Fonte: os autores.

No STJ a situação é ligeiramente melhor. Também nesse tribunal as decisões colegiadas tornaram-se a minoria ao menos desde o início do século. As decisões sobre liberdade de expressão costumavam ocorrer colegiadamente com maior frequência do que no geral, o que se manteve também a partir de 2013. Mas esse patamar mais favorável, que alcançou 53\% em 2015, continua sendo objetivamente muito ruim.

O terceiro e último aspecto que afeta as condições de qualidade para a tomada de decisões é a composição dos órgãos colegiados. $\bigcirc$ que procuro medir na sequencia são as ausências de ministros durante os julgamentos.

É natural que os ministros não consigam comparecer a algumas sessões por motivo de doença ou compromisso no exterior. Muitas vezes a missão de representar o tribunal no exterior 
adquire importância que pode compensar a ausência na sessão. É dizer: existem exceções de força maior que impedem a participação no julgamento. Mas essas ocasiões são realmente minoritárias? Meu objetivo é buscar responder a essa pergunta.

Ausências ocorrem tanto em julgamentos onde a votação é completada e o resultado proclamado, quando naqueles suspensos sem sua conclusão. Nesse levantamento estou considerando apenas as sessões na quais o julgamento foi concluído, ignorando julgamentos suspensos. Entendo que a ausência de um ministro na sessão que foi suspensa poderia minimamente ser compensada pela presença na sessão posterior em que o julgamento pode ser concluído. Isso daria ao ministro a oportunidade de expor seu ponto de vista quando entende necessário, questionar algum argumento discutido anteriormente na sessão suspensa ou pedir esclarecimentos sobre a o voto vencedor antes da proclamação do resultado.

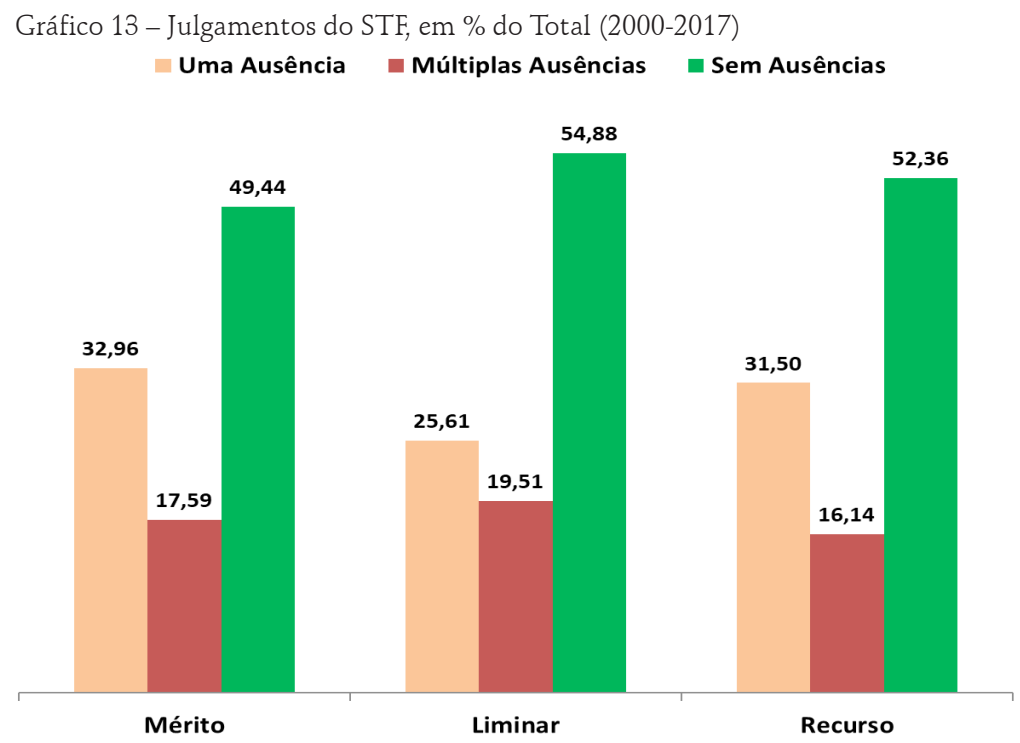

Fonte: os autores.

O Gráfico 14 mostra a proporção de julgamentos das turmas, nos últimos dez anos, com presença de todos os componentes do órgão, com a ausência de apenas um ou de vários deles. Uma em cada cinco decisões liminares é a preciada por apenas três integrantes. Apenas metade das decisões é tomada pela composição completa da turma. 


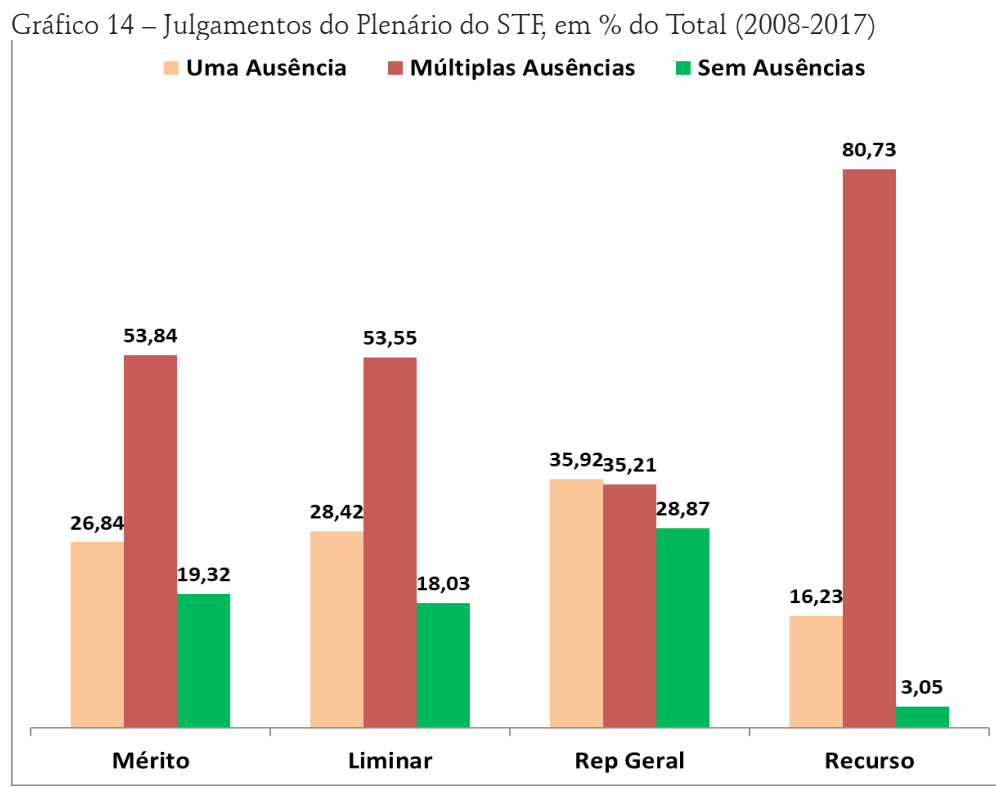

Fonte: os autores.

No plenário a situação é bastante pior. Apenas 3\% dos julgamentos sobre recursos contaram com 11 ministros. 80\% dos julgamentos tiveram mais de um membro do órgão ausente. Nas decisões de mérito apenas uma em cada cinco foi tomada pelos 11 integrantes. As decisões sobre repercussão geral são aquelas que atraem a maior presença, com pouco menos de $30 \%$.

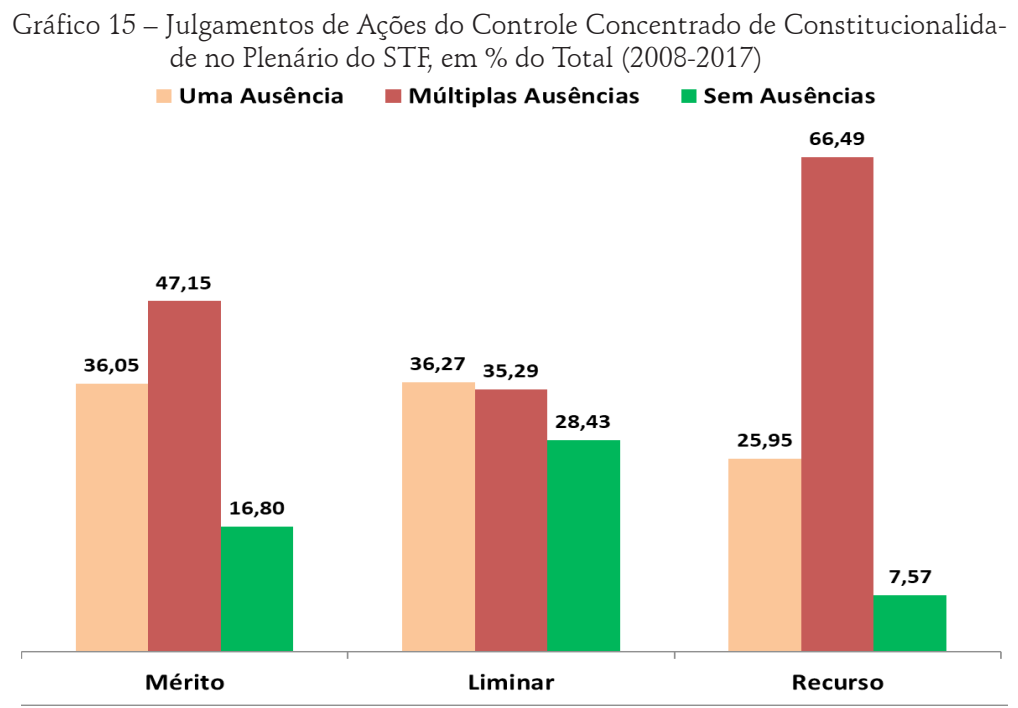

Fonte: os autores.

Nos julgamentos do controle concentrado de constitucionalidade o cenário é até pior quando a decisão é de mérito. Apenas uma em cada seis decisões foi o resultado de deliberação de 11 ministros. Metade delas foi tomada com múltiplas ausências. Isso significa mostra as chances 
de que a totalidade do plenário esteja presente no julgamento da lei do direito de resposta, por exemplo. Cada ausência significa a impossibilidade de contar com argumentos, insights, críticas às demais posições e contextualizações do voto do relator que a Constituição pressupõe necessários ao estabelecer a competência do plenário para o controle concentrado de constitucionalidade. Mas os julgamentos sobre liberdade de expressão seguem esse padrão?

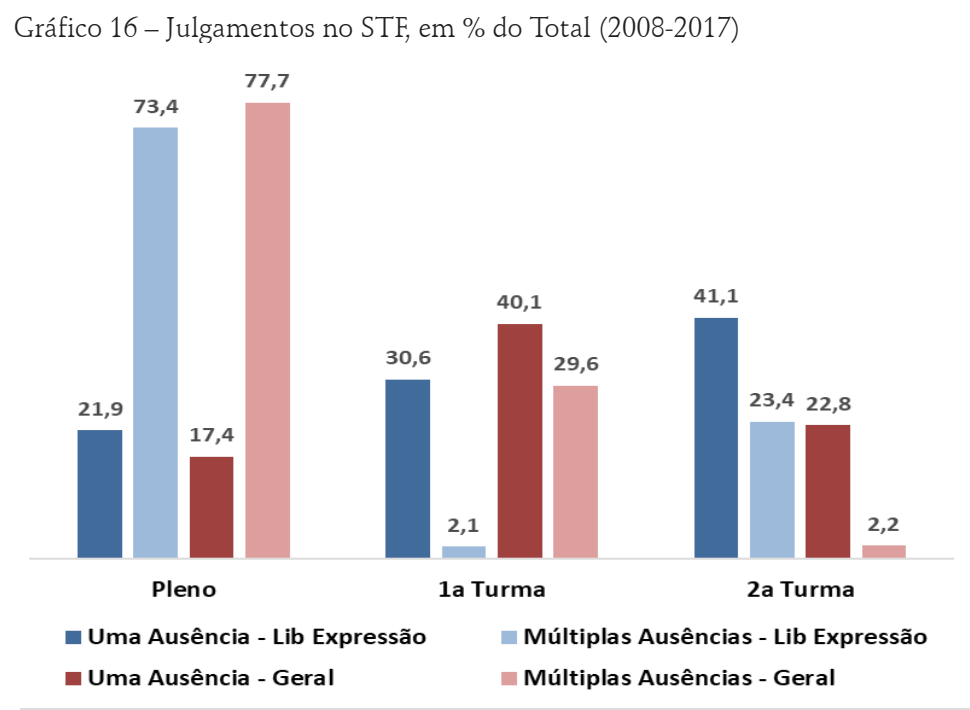

Fonte: os autores.

No plenário a situação parece muito similar entre os julgamentos de liberdade de expressão e os casos em geral. Embora exista uma concentração maior de julgamentos com uma ausência no campo da liberdade de expressão, no caso de julgamentos com múltiplas ausências a proporção é menor. Já nas turmas há uma clara alternância: na $1^{\text {a }}$ turma a situação é bastante pior no geral, enquanto que na $2^{a}$ turma é bastante pior nos casos de manifestação do pensamento. 
Gráfico 17 - Julgamentos com Composição Completa no STF, em \% do Total (2008-2017)

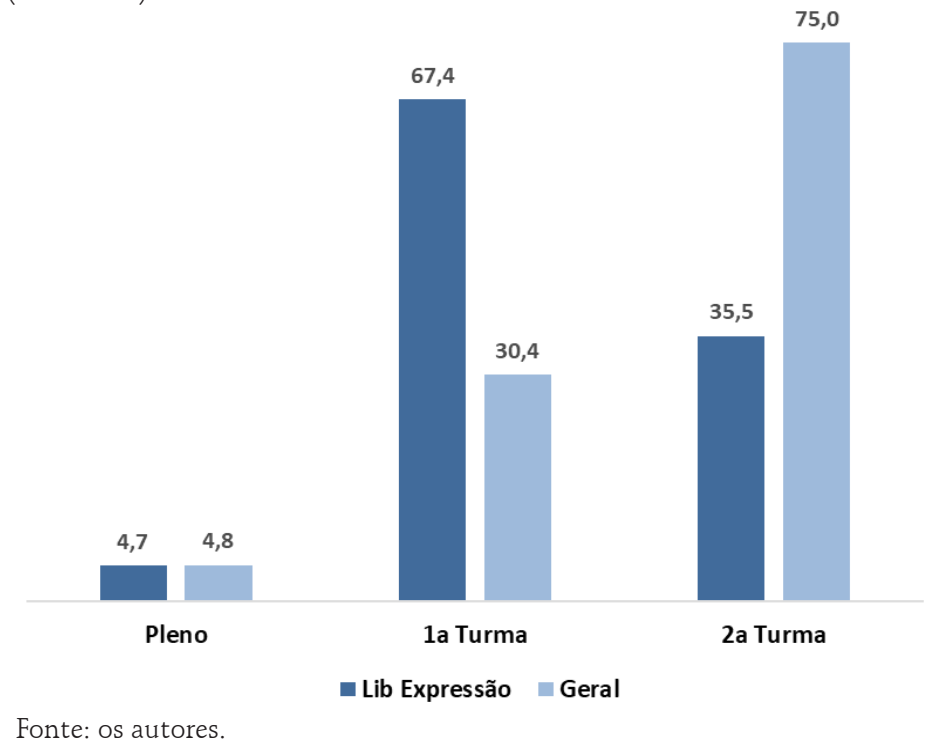

O Gráfico 17 confirma essa leitura ao mostrar apenas as taxas de julgamentos com composição completa. Ainda que exista paridade entre o geral e os casos de liberdade de expressão, o nível é absolutamente baixo: apenas uma em cada vinte decisões contou com 11 ministros apresentando seu voto ou minimamente acompanhando os debates. Mesmo no melhor cenário para as decisões sobre o assunto, na $1^{\text {a }}$ Turma, trata-se de dois terços de julgamentos com todos os 5 presentes.

\section{Conclusão}

O objetivo desse trabalho é apresentar a realidade da aplicação do direito fundamental à liberdade de expressão nos tribunais superiores, de modo a permitir uma contextualização e revisão de numerosas proposições teóricas já encontradas na literatura sobre liberdade de expressão. Ou seja: muito foi dito já sobre como os tribunais superiores deveriam decidir quando está em causa a manifestação de opinião, mas pouco foi apresentado sobre as condições segundo as quais essa atividade judicial ocorre.

Acredito que a ponderação e a proporcionalidade como métodos de solução de conflitos envolvendo direitos fundamentais são as ferramentas mais adequadas à disposição do Judiciário atualmente. Partindo desse pressuposto, a primeira instância e os tribunais superiores exercem papeis obviamente diferentes. A primeira instância é o contexto mais importante de capilarização de técnicas judiciais para adjudicação de direitos fundamentais. É a porta de entrada, o primeiro contato entre a perspectiva subjetiva desses direitos, conforme delineada pela doutrina e jurisprudência, e os titulares dessas posições. Por vezes é o único contato, quando não se recorre. Na outra ponta, o STJ 
e o STF são os responsáveis principalmente, mas não só, por uniformizar as escolhas feitas desde a primeira instância sob o ponto de vista do direito infraconstitucional e constitucional.

Há pouco ou nenhum conhecimento empírico científico sobre o desempenho desses dois papéis no campo da liberdade de expressão. Informações sobre o desempenho do Judiciário nesses quesitos são anedóticas, raramente oferecendo um retrato representativo do todo. A contribuições desse trabalho é suprir parte desse vácuo e levantar dados para traçar a performance do STJ e STF como uniformizadores de decisões nessa área.

Os tribunais superiores lidam com carga de trabalho que inviabiliza qualquer chance de uma análise do direito infraconstitucional ou constitucional aplicado ao caso concreto. As condições nas quais trabalham os ministros impedem a qualidade da prestação. Os tribunais não decidem como colegiado e transformaram-se em um conjunto de decisões monocráticas. A especial atenção ao STF mostra que, mesmo quando o colegiado se reúne com o potencial de fixar os precedentes, tão necessários para o direito constitucional brasileiro na área da liberdade de expressão, os julgamentos são prejudicados por ausências que se tornaram a regra e não mais a exceção. São debilitadas as condições de deliberação para encontrar e consolidar parâmetros - já sugeridos pela doutrina, por sinal - que norteiem o uso da ponderação e proporcionalidade nos casos de livre manifestação, honra e imagem.

Para pensar direitos fundamentais no Brasil atualmente é necessário mais do que apenas discutir as teorias sobre aplicação de normas jusfundamentais. Sob o ponto de vista do constitucionalismo de realidades, é essencial conhecer o contexto no qual o Judiciário e, especialmente, os tribunais superiores decidem sobre o assunto.

\section{REFERÊNCIAS}

AUSTEN-SMITH, David; BANKS, Jeffrey S. Information Aggregation, Rationality, and the Condorcet Jury Theorem. American Political Science Review, v. 90, n. 1, 1996.

BARROSO, Luís Roberto. Curso de Direito Constitucional Contemporâneo. 5. ed. São Paulo: Saraiva, 2015.

CAMINKER, Evan H. Why Must Inferior Courts Obey Superior Court Precedents? Stanford Law Review. N. 46, 1994.

CLÈVE, Clèmerson Merlin; LORENZETTO, Bruno Meneses. Dimensões das Liberdades de Informação e de Expressão: Elementos do Discurso Público. Espaço Jurídico Journal of Law, Joaçaba, v. 17, n. 1, p. 83-98, jan./abr. 2016.

EDELMAN, Paul H. On Legal Interpretations of the Condorcet Jury Theorem. Journal of Legal Studies, v. XXXI, Jun. 2002.

Editorial. Judicial Behavior and Legal Responsiveness. Law \& Society Review, v. 3, 1967. 
EPSTEIN, Lee; LANDES, William M.; POSNER, Richard A. The Behavior of Federal Judges. A Theoretical \& Empirical Study of Rational Choice. Cambridge: Harvard University Press, 2013.

EPSTEIN, Lee; MARTIN, Andrew D. Quantitative Approaches to Empirical Legal Research. In: CANE, Peter; KRITZER, Herbert. The Oxford Handbook of Empirical Legal Research. New York: Oxford University Press, 2010.

FELDMAN, Adam. Counting on quality: The effects of merits brief quality on Supreme Court Decisions. Denver Law Review, v. 94, 2016.

GOLDMAN, Sheldon. Behavioral Approaches to Judicial Decision-Making: Toward a Theory of Judicial Voting Behavior. Jurimetrics Journal, v. 11, 1971.

HARTMANN, Ivar A. et al. A influência da TV Justiça no Processo Decisório do STF. Revista de Estudos Empíricos em Direito, v. 4, p. 38-56, 2017.

HARTMANN, Ivar A.; CHADA, Daniel. A razão sem condições de qualidade. In: VILHENA, Oscar; GLEZER, Rubens (org.). A razão e o voto. Diálogos constitucionais com Luís Roberto Barroso. São Paulo: FGV Direito SP Editora, 2017.

HARTMANN, Ivar Alberto. Regulação da Internet e novos desafios da proteção de direitos constitucionais. O caso do revenge porn. Revista de Informação Legislativa, v. 55, p. 13-26, 2018.

HARTMANN, Ivar Alberto. Carta a um Jovem Pesquisador do Direito. JOTA, 16 maio 2017. Disponível em: https://www.jota.info/carreira/carta-a-um-jovem-pesquisador-do-direito-16052017. Acesso em: 17 jan. 2018.

KLEIN, David O.; WUELLER, Joshua R. Fake News: A Legal Perspective. Journal of Internet Law, v. 20, n. 10, 2017.

KOPPEN, Peter J. Van; KATE, Jan Ten. Individual Differences in Judicial Behavior: Personal Characteristics and Private Law Decision-Making. Law \& Society Review, v. 18, n. 2, 1984.

LADHA, Krishna K. The Condorcet Jury Theorem, Free Speech, and Correlated Votes. American Journal of Political Science, v. 36, n. 3, 1992.

LEAL, Fernando. Até que ponto é possível legitimar a jurisdição constitucional pela racionalidade? Uma reconstrução crítica de "A razão sem voto". In: VILHENA, Oscar; GLEZER, Rubens (org.). A razão e o voto. Diálogos constitucionais com Luís Roberto Barroso. São Paulo: FGV Direito SP Editora, 2017.

MELLO, Patrícia Perrone Campos. Precedentes e Vinculação. Instrumentos do Stare Decisis e Prática Constitucional Brasileira. Revista de Direito Administrativo, n. 241, 2005.

MELLO, Patrícia Perrone Campos. Precedentes Vinculantes nos Estados Unidos da América e no Direito Brasileiro: Um Estudo Comparado. Revista de Direito Internacional, v. 13, n. 3, 2016.

NERIS, Natália; RUIZ, Juliana Pacetta; VALENTE, Mariana Giorgetti . Análise Comparada de Estratégias de Enfrentamento a 'Revenge Porn' pelo Mundo. Revista Brasileira De Políticas Públicas (RBPP), v. 7, p. 1-1, 2018. 
NUMBER of monthly active Facebook users worldwide as of 3rd quarter 2017 (in millions). Statista, [201-]. Disponível em: https://www.statista.com/statistics/264810/number-of-monthly-active-facebook-users-worldwide/. Acesso em: 27 jan. 2018.

SCHAUER, Frederick. Fear, Risk and the First Amendment: Unraveling the Chilling Effect. Boston University Law Review, n. 58, 1978.

SCHAUER, Frederick. Incentives, Reputation, and the Inglorious Determinants of Judicial Behavior. University of Cincinnati Law Review, v. 68, 2000.

SCHREIBER, Anderson. Marco Civil da Internet: Avanço ou Retrocesso? A responsabilidade civil por dano derivado do conteúdo gerado por terceiro. In: LUCCA, Newton de; SIMÃO FILHO, Adalberto; LIMA, Cíntia Rosa Pereira de (coord.). Direito e Internet III. Tomo II. São Paulo: Quartier Latin, 2015.

SILVA, Virgílio Afonso da. Deciding without Deliberating. International Journal of Constitutional Law, v. 11, n. 3, 2013.

SUNSTEIN, Cass; SCHKADE, David; ELLMAN, Lise Michelle. Ideological Voting on Federal Courts of Appeals: A Preliminary Investigation. Virginia Law Review, v. 90, n. 1, 2014.

SWEET, Alec Stone. Constitutional Courts. In: ROSENFELD, Michel; SAJÓ, András. The Oxford Handbook of Comparative Constitutional Law. Oxford: Oxford University Press, 2012.

ULMER, S. Sidney; STOOKEY, John A. Nixon's Legacy to the Supreme Court: A Statistical Analysis of Judicial Behavior. Florida State University Law Review, n. 3, 1975.

WALDRON, Jeremy. The Harm in Hate Speech. Cambridge: Harvard University Press, 2012.

WEDEKING, Justin; ZILIS, Michael A. Disagreeable Rhetoric and the Prospect of Public Opposition: Opinion Moderation on the U.S. Supreme Court. Political Research Quarterly, 2017.

YATES, Jeff; MOELLER, Justin; LEVEY, Brian. 'For the times they are a-changing': Explaining voting patterns of U.S. Supreme Court Justices through identification of micro-publics. BYU Journal of Public Law, v. 28, 2013. 
